\title{
The Limits of Instrumentalism: Informal Work and Gendered Cycles of Food Insecurity in Mozambique
}

\section{Abstract}

The instrumentalist literature suggests that women can help achieve household food security if they have access to productive resources but do not become overburdened as a result. This paper seeks to assess the relevance of this literature by exploring the gendered cycles of food insecurity in the context of women's informal labour in northern Mozambique. It considers the relation between women and food security as embedded in the broader socio-economic setting, and finds that the interaction of different forms of deprivation, such as lack of secure employment and conflicting labour demands, generates food insecurity.

\section{Introduction}

Much literature on women and food security suggests that women tend to channel more resources into food expenses and child feeding, relative to men, and therefore women's access to productive resources is critical to food security and child nutrition (Quisumbing and Maluccio 2000; Duflo 2003; Doss 2005; Lépine and Strobl 2013). However, time scarcity could potentially have adverse consequences: as women dedicate greater shares of their time to employment, less time may be available for child care and food preparation, with negative repercussions on food security (Quisumbing et al. 1995; Kadiyala et al. 2014).

This paper develops an analysis of the gendered cycles of food insecurity in the province of Cabo Delgado, northern Mozambique, by looking at women's access to earned incomes, time use patterns and agricultural wage employment. Its main aim is to assess the relevance of the literature on women and food security in the context of informal women's labour, and processes 
of livelihood diversification and social differentiation that characterise Cabo Delgado as well as other regions in sub-Saharan Africa.

This study shows that different forms of deprivation, such as lack of secure employment and multiple labour demands, interact with each other and lie at the basis of the production of vicious cycles of food insecurity. Vulnerability to food insecurity develops through gendered dynamics and processes of social differentiation that make poorer, food-deficit households and those where women are the main earners more exposed to the risk of food insecurity.

Despite the affirmation of instrumental approaches to gender equality, ${ }^{\mathrm{i}}$ which see gender equality as conducive to poverty reduction and well-being promotion, close examination of the causal mechanisms has been lacking (van den Bold et al. 2013). This paper expands limited efforts to unpack the chain linking gender equality and well-being (Duvendack and PalmerJones 2016; Garipati et al. 2016) using detailed micro-level evidence. In so doing, it extends the critique of instrumentalist approaches to gender equality and well-being (O’Laughlin 2007; Wilson 2015; Gideon and Porter 2015) by showing that the relation between women and food security needs to be situated in the context of women's informal labour, and of processes of livelihood diversification and social differentiation. Thus it confirms the necessity to address the vulnerability caused by informal and unsecure employment in sub-Saharan Africa (Meagher 2016). Instrumentalism fails to contextualise these relations due to its universalistic demands.

The paper begins by providing a critical review of the dominant literature on women and food security. Then section 3 provides a description of study setting and methodology, with a specific discussion of food security indicators. The analytical sections, based on primary research conducted in the northernmost Mozambican province of Cabo Delgado, are structured as follows. First, I look at multiple occupations, irregular streams of income and food 
consumption. Second, the relevance of gendered time constraints for food practices is explored. Third, I analyse the interaction between seasonality, wage work in agriculture and multiple labour demands in the production of vicious cycles that contribute to food insecurity.

\section{Debates on women and food security}

A large body of literature shows that women's control of productive resources - including earned incomes, transfers and assets - tends to translate into better well-being outcomes, especially in relation to child health, nutrition and education. ${ }^{\text {ii }}$ Thomas $(1990,1997)$ conducted some of the earliest and most cited studies in this area and, using data from the Household Budget Survey (HBS) in Brazil, found that women's nonwage incomes are positively associated with household calorie and protein intake as well as with child nutritional status. Another influential study, Smith et al. (2003), draws on Demographic Health Surveys (DHS) data from 36 countries in the global South and concludes that women's status ${ }^{\mathrm{iii}}$ is positively associated with child nutrition. Many other more recent studies confirm positive correlations between various measures of gender equality and nutrition indicators. For example, Doss (2005) finds that in Ghana women's increased shares of farmland are associated with higher budget shares spent on food and education and lower budget shares spent on alcohol, durable and nondurable goods. Duflo (2003) shows that, in South Africa, pensions received by women improved the nutritional outcomes of girls but not those of boys. Lépine and Strobl (2013) find that women's bargaining power is a strong determinant of child nutrition in Senegal. The main mechanism identified is that women's control of greater shares of household resources leads to changes in household spending and consumption patterns in favour of food expenses, which in turn contribute to improved food security and nutrition (Quisumbing and Maluccio 2000; Duflo 2003; Smith et al. 2003; Doss 2005; Lépine and Strobl 2013; van den Bold et al. 2013; Malapit et al. 2015). 
This body of literature constitutes the backbone of the well-being argument for gender equality, a more recent companion of the efficiency argument (O'Laughlin 2007), whereby women's access to productive resources is seen as conducive to improved well-being. Gender equality for economic growth and well-being has become a World Bank's mantra, summed up in the slogan 'gender equality as smart economics' (WDR 2012), and has been taken up by most development actors, including the world's most influential philanthropic organisation, the Bill and Melinda Gates Foundation (Fejerskov 2016).

The instrumentalist literature makes a universalistic economic case for gender equality that has been influential in policy making. The case has universal scope as it is deemed applicable across contexts. An important contribution of the literature is that it highlights the gendered nature of food security and intra-household inequality. In more recent developments, claims on the instrumental potential of women's empowerment have been partly toned down, with the recognition that empirical evidence is more mixed than often assumed and that there is greater use of mixed methods (van den Bold et al. 2013, 2015). However, the key problem of the instrumentalist literature is that, due to its universalistic demands, it fails to locate the relation between women and food security in specific socio-economic, historical and political contexts.

Within the boundaries of the instrumentalist paradigm, we see the rise of concerns with women's time constraints, a factor that can potentially reverse the positive correlations between gender equality and nutrition. Time scarcity can have negative effects on care practices, which in turn affect nutrition by limiting the time that can be devoted to feeding and cooking, health and hygiene practices (Quisumbing et al. 1995; Kadiyala et al. 2014). This type of concern is partly manufactured by the same programmes that encourage women to engage in commercial agriculture, cash-generating activities, training schemes and the like (Stevano et al. forthcoming). As women do more work outside their homes, will they lose their ability to deliver better well-being outcomes to their families? Many have investigated the effects of 
maternal employment on child nutrition, and obtained mixed results (Martin and Lippert 2012; Datar et al. 2014). Several studies indicate that other factors, such as household composition, work intensity, socio-economic status and seasonality, mediate and differentiate the nutritional implications of time use patterns (Ricci et al. 1996; Jackson and Palmer-Jones 1998; Jones et al. 2012; Ziol-Guest et al. 2013; Johnston et al. 2015).

Gendered time constraints ought to be taken into consideration, as evidence has undermined assumptions on the abundance of time for labour available to the poor, especially if women (Wilson 2015). Lack of infrastructure and the burden of reproductive work can create time constraints amidst underemployment (Bardasi and Wodon 2006). However, analyses of gendered time use, and constraints, need to be conceptually strengthened so as to be situated in the organisation of economic activity and patterns of economic development. For instance, in a study of women traders in Kumasi (Ghana), Clark (1994) documents tensions that arise between trading activities and the practices of cooking and child care. Clark explains that time patterns of meal preparation and trading activities clash, but wealthier traders manage to minimise these problems by hiring maidservants. In northern Zambia, Moore and Vaughan (1994) see the introduction of hybrid maize cultivation as a triggering factor for increased women's agricultural and house work, but observe that time burdens are not experienced equally by all women, depending on the household's socio-economic status and development cycle.

Conceptually-enriched approaches to the study of gendered time burdens pave the way for an understanding of the relations between women and food security that moves away from the dataset-based, quantitative and ahistorical approaches feeding the instrumentalist agenda.

Growing empirical evidence shows that women tend to concentrate in survivalist activities, which cast doubts on the potential for women's economic empowerment via small-scale selling 
and trading activities (Meagher 2010). In African countries, women’s participation in paid work and cash-earning activities is seen as resulting from decreasing (male) employment associated due to Structural Adjustment, male migration and associated processes of livelihood diversification (e.g. Meagher 1995; O’Laughlin 1998; Whitehead 2009). A central question that this paper sets out to address is on the relevance of the well-being argument for gender equality in the context of women's participation in informal employment and livelihood diversification (Meagher 2016). Poor consideration for broader socio-economic and historical context has led much instrumentalist literature on women and food security to inadequately consider variation in women's living and working conditions, which instead must be taken into account to understand the gendered nature of food security.

\section{Study setting, methods and food security indicators}

Cabo Delgado is the northernmost province of Mozambique. Agriculture is an important source of livelihoods but its potential remains underexplored, with fragmented agricultural intensification mostly concentrated in the southern districts of the province, closer to the Nacala development corridor (Stevano 2013). Cabo Delgado is one of the Mozambican provinces that are experiencing the expansion of resource extraction in the country, due to the discovery of natural gas just off its shores. However, it is not yet clear what impacts this discovery will have on the welfare of the local population. Over the past decade, rapid economic growth has not led to falling poverty in Mozambique (Cunguara and Hanlon 2012). The recent news, at the time of writing, on the debt crisis in Mozambique threatens hopes that years of sustained economic growth will produce welfare gains for Mozambicans. ${ }^{\text {iv }}$ Governmental assessments emphasise high levels of vulnerability due particularly to lack of employment opportunities (MPD/DNEAP 2010). The levels of chronic malnutrition in the province were the highest 
nationally in 2008, with 56 per cent of children under five affected by stunting (MICS 2008) and, despite having decreased, they remain at 52 per cent in 2011 (DHS 2011). In addition, food consumption data suggests that 36 per cent of the population in Cabo Delgado has inadequate diets, with narrow dietary diversity (WFP 2010).

This paper draws on research conducted in the province of Cabo Delgado in 2011 and 2012. Data were collected in three districts: the town of Pemba (urban district), Metuge (peri-urban district) and Mueda (rural district), highlighted in the map below. These sites were selected to gain a perspective on women's work across urban and rural areas, as well as intra-regional variation in food access and consumption.

Figure 1.

Data collection was structured in three consecutive phases feeding into one another: qualitative-quantitative-qualitative. Qualitative methods included participant observation, structured and non-structured interviews and life histories with women, members of their households and communities. The quantitative phase consisted of the implementation of a household survey, as part of which 120 households were randomly selected across the three districts, and one woman was interviewed in each household. ${ }^{\mathrm{v}}$ Table 1 summarises the descriptive statistics of the survey sample.

\section{Table 1.}

The mixed methods approach contrasts with the dominant quantitative studies of the relation between women and food security, and is aimed at testing whether the positive well-being argument holds when the relation is embedded in its context. The key features of each phase of primary research are summarised in Table 2

Table 2. 
Mixed methods also helped look at food practices from different angles, and expand the scope of food research beyond common quantitative assessments of household food consumption and food security. The introduction of the notion of food security, linked to Sen's Entitlement Approach (Sen 1981), placed the emphasis on the mechanisms through which people access food, thus moving the focus from food supply to food demand. Food security can be seen as embodying both a quantitative and a qualitative component (Smith et al. 2006).

The quantitative aspect of household food insecurity broadly refers to ensuring consumption of adequate quantities of food and number of daily meals. It can be measured with a variety of indicators such as food-frequency questionnaires and the Household Hunger Scale (Deitchler et al. 2010; Deitchler et al. 2011; Ballard et al. 2011). As for food quality, a good proxy indicator is dietary diversity, which captures how food consumption is distributed over different food groups and gives an assessment of how diversified and balanced diets are (Ruel 2002).

A cross-cutting feature of food security indicators is that they are snapshot-based. They capture the state of food security, at specific points in time, normally over a reference period of 24 hours, in the case of dietary diversity, or seven days or longer, for other indicators of food consumption. They can be repeated over time to gain a picture of change, but they are ill-suited to look at the processes underlying the production of food insecurity. As chronic malnutrition is severe in Cabo Delgado (DHS 2011), it is important to understand the vicious cycles that lead to food insecurity using more dynamic analytical approaches. Conventional tools, such as FANTA’s Household Hunger Scale (HHS) and Household Dietary Diversity Score (HDDS), were used in combination with other qualitative methods. This allowed for a comprehensive study of food, which looked at the nature of food insecurity and its determinants in Cabo Delgado. Growing attention to nutrition-sensitive interventions highlights the need to understand and tackle the underlying determinants of malnutrition (Ruel and Alderman 2013). 


\section{Results}

\subsection{Multiple occupations, fluctuating incomes and food consumption}

The household survey shows that women in Cabo Delgado engage with a combination of wage work and cash-generating activities, in addition to farming their machambas (land plots): 74 per cent of the sample reported performing paid work or cash-earning activities in the year before the interview. Women take up a variety of paid jobs, mostly agricultural wage work, and cash-earning activities, such as trade of agricultural produce, preparation and sale of food and drinks. These yield varying earnings and are sometimes performed regularly but more often seasonally or sporadically. The lack of regular employment opportunities and the associated high degree of economic informality translate into unstable working patterns, which produce irregular and multiple streams of income. Often all household members are forced into cashearning activities as households need to diversify their productive activities in order to survive. Fluctuating and multiple incomes determine consumption practices, including food expenses, as it is detailed below.

In Cabo Delgado, household basic expenses are normally managed through a gendered system of cash allowances. A cash allowance is a variable amount of money that is handed over from an individual to another, most often from a man to a woman, through family ties. The size and the frequency of cash allowances are determined by income levels, household's expenditure planning and relative bargaining power of household members. Of the women interviewed as part of the survey, 72.5 per cent receive a cash allowance. They receive it from the husband (66 per cent) or another family member, often their brother (6 per cent).

Cash allowances are used to buy food on a daily basis, clothes for all household members, dishes, soap, charcoal and water. All of these expenditures are normally taken care of by women, or by children on their behalf, but mostly with men's incomes. Nevertheless women's earnings are also used to buy food (78 per cent of cash-earning women ${ }^{\mathrm{vi}}$ in the sample), house 
goods (50 per cent), and school-related expenses (27 per cent). Thus women's incomes complement men's incomes, and replace them when necessary.

For example, consider the story of Zaina and João, a married couple living in Namuapala, in the district of Metuge. Zaina prepares and sells mandaze (balls of fried bread, common street food) and alcoholic drinks throughout the year. João manages their land plots, and sells agricultural produce and seeds. This revenue tends to be lumpy because sales of agricultural produce and seeds are concentrated at particular times of the year. Hence when João's income is available it covers all household consumption and, when it runs out, then they rely on Zaina's cash earnings. Similar practices, which were observed in other households, show the gendered character of income use and also the importance of management of multiple and irregular streams of income.

What are the implications for food consumption? Irregular and multiple occupations result in likewise irregular and multiple cash flows. In turn, cash fluctuations determine the types of foods purchased. Food purchase is a ubiquitous strategy of household food provisioning, with all households interviewed in the survey reporting to have bought food in the month before the interview. Own-produced food is also important, with 75 per cent of the households retaining some agricultural produce for family’s consumption. However, no household could entirely rely on own-grown food, which shows the significance of food purchase.

Cash allowances are the primary source of income for daily food expenses. Women's management of cash allowances is aimed at smoothing a lump sum over a period of time, so that it can be used to purchase food in different days. If they receive a cash allowance, then women may use their incomes in a complementary way: respondents explained that they buy foods that they cannot afford regularly. They buy fish or meat, instead of beans for instance. They buy soft drinks, packaged biscuits and mandaze for their children and themselves. 
However, when incomes are too low or seasonal, or when cash allowances are not handed out on a sufficiently regular basis, then the practice of smoothing food consumption over time may be difficult to sustain and, by consequence, food expenses will fluctuate. As the daily food expenses normally concern the ingredients to make the relish, then short-term cash fluctuations are likely to determine the type of relish that accompanies the staple food. For instance, this may result in the purchase of leaves rather than fish or meat. Women's daily availability of cash is likely to fluctuate due to variation in daily earnings from cash-generating activities and agricultural casual wage work.

The ingredients used to prepare the relish - including leaves, legumes, fish or meat - are important to diversify diets. Inability to buy different ingredients has implications for quality and diversity of food consumed. Analysis of dietary diversity data, based on the HDDS indicator, indicates high consumption of cereals: 91 per cent of the respondents reported that someone in their households had consumed cereals, mostly xima (maize porridge) and rice, on the day before the interview. High levels of consumption were also recorded for vegetables (72 per cent), legumes and nuts (56 per cent), and oil and fats (51 per cent). In contrast, extremely low consumption of fruit, meat and milk emerged from the survey data, with percentages of non-consumption above 90 per cent for all of these food categories. Overall, diets in Cabo Delgado are poorly diversified and overly dependent on cereals, vegetables, legumes and, to an extent, cooking oil, a result that provides support to studies that identified narrow dietary diversity as one root cause of food insecurity (MISAU 2010; WFP 2010). The key finding presented in this section is hat low and fluctuating incomes jeopardise households' ability to diversify their diets by impacting daily food expenses.

\subsection{Time constraints and food consumption}

An employment scenario characterised by unstable and multiple occupations shapes food consumption patterns through fluctuating incomes and food expenditure. Does it also create 
tensions on labour demands that have implications on people's ability to consume sufficient quantities of good quality food?

\subsubsection{Gendered dynamics of unpaid care work}

Women are responsible for the act of cooking. The spaces where food preparation takes place are gendered and accessed only by women. While food production (in food-growing households) and acquisition are shared between men and women in various and changing ways, food preparation is undoubtedly a female duty.

'Foodstuff is only for women but taking care of the machamba is for the couple' (focus group with women, Mueda)

Not only is food preparation a female task but, in households where there are women of different age, the responsibility is transferred from older to younger women. In some interviews, it was explained that this is a way to teach younger women how to cook.

'I learnt how to cook with my mother and I still cook in the same way. [...] I remember that once I cooked not well-mixed madranga (cassava porridge) and my mother told me off' (life history interview with Edna, Metuge)

Age-based division of labour within a realm that is female-dominated suggests that to assess how time may impact food consumption patterns, it is not sufficient to look only at women's time but also at household composition, namely at the presence of members who can take up unpaid care work, such as cooking, child care and other house chores. Many of the women interviewed as part of the survey (63 per cent) said that there are other household members who help them with house work. These are mostly grown-up children - typically boys up to a certain age and women of any age - and, at times, grandchildren, nephews or nieces. Within the sample, 28 respondents are cash-earning mothers of young children whose paid work or cash-earning activity entails staying away from home; of them, half said that they carry the children with them while the other half leaves them with other household members. 


\subsubsection{Gendered time constraints and food practices}

Labour transfers within and across households can act as a mitigating factor to time and work burdens, but may not be sufficient to address all constraints. In Cabo Delgado, the preparation of a meal can take from one to several hours (depending on whether women need to grind maize or cassava manually), which, together with the time needed for other daily house chores such as washing clothes and dishes, keeping the yard clean, getting water, firewood or coal for cooking, represents a substantial amount of time of daily reproductive and productive activities.

When house work is combined with agricultural work and other activities, which may involve travelling, then sharing tasks with other household members may not offset time constraints entirely. For instance, consider Flora's typical day. To run her vegetables stall at the market, Flora wakes up at 5am every morning. She needs to arrive at 'Nbanguia (Pemba's wholesale market) sufficiently early to collect supplies for the day. Then she goes to her stall and finishes work when her matapa (leaves) is sold, which varies but it is normally at around 3pm. Flora purchases food with her daily earnings, then goes home and cooks for her family, composed of the husband and her two-year old son. Food is hardly ever ready before 5pm. This means that she rarely has two complete meals per day. Sometimes, when her sister-in-law is visiting, she cooks for the family while Flora is at the market.

The stylised account of Flora's typical day highlights two important aspects for food consumption. First, there is a trade-off between staying at the market and preparing food for her family. Second, reducing the number of daily meals is a response to time constraints. I analyse them in turn.

In contexts where households need to diversify their sources of income due to low levels of earnings and lack of employment opportunities, the delicate task of prioritising some activities over others has implications on the outcomes of both reproductive and productive activities. 
This holds for both women and men. Yet, existing literature suggests that men tend to perform their activities sequentially while women may need to carry out paid and unpaid work simultaneously, thus facing more severe time constraints (Blackden and Wodon 2006). Many women perform their paid work or cash-generating activity on a sporadic basis due to their care obligations. This is especially visible in rural areas, where households tend not to have regular sources of income and therefore need to pursue agricultural work alongside a number of different economic activities. The survey data shows that proportionally more women in rural areas (87.5 per cent) perform wage agricultural work and other cash-earning activities, such as petty trading, relative to their urban counterparts (47.5 per cent). I argue that this finding, which contrasts with images of women in cash-earning activities as mostly an urban phenomenon, is to be explained in relation to men's incomes. As men are more likely to find a job that pays a regular salary in urban areas, this may reduce the need for women to engage in incomegenerating activities. vii

Looking at patterns of response to time constraints, survey data indicates that 43.3 per cent of the respondents skipped a meal in the past month due to lack of time to prepare it and 31 per cent of them said this happened between 3 and 10 times, thus suggesting that lack of time is not to be overlooked as a determinant of food vulnerability. Of the households that skipped a meal due to lack of time to prepare it, a striking 89 per cent are rural households. The association between district of residence (i.e. urban vs rural) and skipping a meal due to lack of time is also highly significant, with a p-value of 0.000 . This data suggests that lack of time for food preparation is mostly a rural phenomenon, which can be interpreted in two, nonmutually exclusive, ways. First, agricultural work is particularly time-consuming and clashes with meal preparation times and, second, multiplicity of occupations may be more pronounced in rural areas, relative to urban ones. Agricultural work begins at dawn, which may imply skipping breakfast and replacing it with a snack, such as fresh or dry cassava. Also, farmers 
and agricultural workers normally return from the fields in the early afternoon but, at times, they may need to work for longer, which often results in skipping lunch and having a full meal only upon return from the fields.

The incidence of time constraints is reflected in the organisation of daily food activities. A widely observed practice consists in cooking the starch component of the meal every time a meal is consumed while the relish may be cooked only once a day. This has two implications. First, even when two meals per day are consumed, it can happen that the same meal is eaten for lunch and dinner. Second, the repetition of meals may lead to recusar comida (refuse food) for being tired of having the same meal more than once in a day. A remarkable 65 per cent of the respondents reported that someone in their household had rejected a meal to avoid repetition in the past month. The HDDS confirmed this pattern, with 20 per cent of the respondents reporting to have had the same meal twice on the previous day.

\subsubsection{Lack of time, lack of resources and poor food consumption}

It is misleading to interpret meal repetition only as caused by lack of time. Considering the high percentage of households that reported having only one complete meal in the day before the interview (50.8 per cent), the practice of repetition is to be seen as an outcome of the combination of time and other forms of deprivation, such as lack of resources to acquire food.

'We don't have either time or foodstuff to have breakfast!' (focus group with women, Metuge)

Households facing time constraints may also be more likely to be exposed to economic ones. One possibility offered by the survey data is to look at the households that skipped a meal due to lack of preparation time by wealth quartile. viii

Figure 2. 
The graph shows an interesting picture. Incidence of time poverty to prepare meals is lowest in the wealthiest quartile. This finding confirms that wealthier households have more resources to minimise time poverty. Wealthier households may dispose of more labour, due to household composition or ability to mobilise extra labour when needed. ${ }^{\text {ix }}$ Interestingly, the highest percentage of households facing time constraints is found in the second quartile, not in the poorest. This may be explained by the fact that levels of wealth are so low in the first quartile that these households lack the economic capacity to diversify their livelihoods by engaging in multiple activities, which translate in reduced exposure to time constraints for food preparation.

The key finding is that gendered time use patterns, and the associated time constraints, shape food consumption patterns and have implications for food insecurity. However, time scarcity is especially critical when experienced in combination with income poverty. Lack of resources can exacerbate time constraints and lead to poor food consumption practices, which in turn contribute to the production of food insecurity for the most vulnerable.

\subsection{Seasonality, agricultural wage work and multiple labour demands}

As the interaction of different forms of deprivation is detrimental for food security, the implications of multiple labour demands is analysed for a vulnerable group of workers: casual wage agricultural labourers. As it is explained below, casual work in agriculture is a crucial source of income for poor food-deficit households.

Existing literature discusses the association between casual wage labour (ganho-ganho) and deepening chronic and acute food insecurity (Devereux 2009). For instance, Bryceson (2006) uncovers the interactions between food uncertainty, recourse to occasional agricultural work as a source of day-by-day food and increased HIV/AIDS risk in the context of the 2001 famine in Malawi. Her analysis is convincing in the extreme circumstances created by the famine; however, it overlooks the normality aspect of casual wage labour. Ganho-ganho in Cabo Delgado is certainly more than a coping strategy. It is a system of labour relations entrenched 
in processes of social differentiation, which are to a degree sharpened by seasonality: poorer households are forced to sell their labour force, especially in the rainy season.

\footnotetext{
'It is possible to do chibalugwa (ganho-ganho in Shimaconde) in the machambas of the antigos (people who fought the independence war and now receive a pension) and those who have a barraca (small stall/shop) or a good negócio (business activity)’ (Muanaidi, farmer and casual agricultural labourer, Mueda)
}

The survey data speaks clearly for the incidence of seasonality on food reserves and casual wage labour. Among the interviewed households, 95 out of 120 have access to one machamba or more, and most farming households grow maize, which is the most important staple in Cabo Delgado. Only 23 respondents reported that their maize production was sufficient to meet the household's needs for the entire year. A great percentage of households, 48 per cent, faced own-produced maize shortages for periods of four months or longer. The bulk of this group food-deficit households - exhausted their maize supplies during the rainy season, between December and February. The strategies adopted to overcome these shortages are various: replacement of maize with cassava, purchase of staples, casual wage labour on other people’s fields, and borrowing food from relatives. These practices are not mutually exclusive and many households resort to a combination of them.

Maize shortages are an imperfect indicator of food insecurity because some households with access to off-farm income may rely on purchased food. However, there is also clear evidence that off-farm income is re-invested in agricultural labour to boost agricultural production, and ensure regular food supplies and agricultural produce for sale. ${ }^{\mathrm{x}}$

Looking at the data on hiring and selling agricultural labour should help delve into this question. Among the respondents, 37.5 per cent of the sample reported that one or more household member(s) worked as occasional agricultural labourers in the previous year. A smaller percentage, 17.5, hired agricultural workers. These percentages show an imprecise 
correspondence between the number of food-secure households and labour-hirers and, likewise, between food-deficit households and the incidence of casual wage labour. However, expectedly, there are some discrepancies that highlight that a number of households have food deficits but are not food insecure because they purchase food.

Casual wage labour is one important response to seasonal food scarcity and temporary cash needs, accessible especially to poorer rural households. In interviews, ganho-ganho was always described as a long established practice, which is normally paid in cash. Each task is assigned a pay rate that tends to be homogeneous within villages (or districts) but diverse across them. It can take one to a number of days to complete a task, depending on the task itself and on the worker's physical strength.

In Cabo Delgado, ganho-ganho is mostly seasonal, because of households' limited ability to hire labour. In qualitative interviews, a few households reported hiring agricultural workers throughout the year, and only one survey respondent said that her household contracts agricultural workers on a regular basis. Thus labour-hiring households that contract wage labour seasonally are more numerous than those who can hire workers on a regular basis. This results in concentration of agricultural wage work opportunities in a period of approximately three months, during the rainy season.

The seasonal character of ganho-ganho means that, despite the general lack of employment opportunities in Cabo Delgado, some rural households can face labour shortages in the rainy season. ${ }^{\text {xi }}$ The majority of casual wage labourers interviewed said that they would do this job more regularly if there were more opportunities throughout the year. However, some respondents said that they did it only a few times in an entire rainy season because they had to work on their own machamba, especially at the time of the year when agricultural work is most labour-intensive. 
'It is possible to do chibalugwa before the beginning of the rainy season: men clear the land and women do 'hoe work' and seeding. [...] I do chibalugwa only once or twice per year because I have work to do on my own machamba' (life history interview with Muanaidi, farmer and occasional agricultural labourer, Mueda)

At the centre of the matter lies the re-iterated partial reliance on production for own consumption that households seek to maintain to meet their food requirements and social costs of production. ${ }^{\mathrm{xii}}$ O’Laughlin (2013) argues that non-commodified production and use of casual wage labour are two tendencies that are embedded in the ways class, gender and race shape rural health in contemporary southern Africa: xiii

‘[... The precariousness of casual work demands that workers have some other additional livelihood base. Doing casual labour can help poor rural farmers to defend a livelihood in times of crisis, but it can also prevent them from securing one.' (O’Laughlin 2013: 181)

It is evident that the multiplicity of occupations, which originates from thin or absent employment opportunities, can sustain livelihoods while keeping them insecure, with severe implications for food security. Seasonality creates a strain on households that are forced into ganho-ganho that has broader implications than immediate reduced (food) consumption. It does affect their productive and reproductive practices in ways that contribute to the reiteration of vicious cycles of poverty and food insecurity.

Tensions on labour demands are especially visible for women, relative to men. Women face more severe constraints due to their reproductive responsibilities. In the survey interviews, it emerged that men in the household had performed ganho-ganho more frequently than women. Women's capacity to earn an income from ganho-ganho tends to be more constrained than that of men, although in all research sites respondents explained that pay rate by task is equal for women and men. Seasonal wage labour exemplifies the tensions between reproductive and productive work, but also trade-offs among productive activities - i.e. farming own land or working as a ganho-ganho worker. 
In sum, the effects of seasonality on labour demands describe the production of food insecurity over time via arising constraints on household practices of labour allocation. Patterns of social differentiation imply that seasonality and casual wage labour in agriculture have critical consequences for food consumption and security for the most vulnerable households. The households that are most prone to this type of vulnerability are food-deficit households that need to resort to casual wage work in agriculture during the rainy season and, due to the gendered character of reproductive work, those households where women are the main earners. An analysis of these processes highlights the gendered dynamics that underlie the cyclical production of food insecurity.

\section{Conclusions}

An influential body of literature has convinced us that women can help achieve household food security via increased access to productive resources. However, this may go wrong if women become overburdened. The problem with a great part of this body of work is that it abstracts the study of the relation between women, food security, and time constraints from the socioeconomic and historical contexts in which they are embedded. This paper used an innovative conceptual and methodological approach to study the gendered determinants of food insecurity in northern Mozambique, a setting characterised by predominance of informal and casual labour.

A mixed-method, gendered and historicised analysis made it possible to capture three key dynamics that shape the gendered cycles of food insecurity in northern Mozambique. First, lack of regular employment gives rise to the need to engage in multiple occupations, which in turn produce multiple and irregular streams of income. Fluctuating household incomes shape food expenses, and jeopardise households' ability to diversify their diet. 
Second, time constraints matter for food consumption practices and need to be considered as interacting with other forms of deprivation. The evidence presented in this paper indicates that poorer households are likely to be more exposed to time scarcity, with negative implications for food security. The gendered organisation of work, particularly agricultural work, in Cabo Delgado clashes with food preparation times, and results in reduction or repetition of meals.

Third, agricultural wage work creates multiple labour demands for poor households at particular times of the year, due to the seasonal character of agricultural work in Cabo Delgado. The tensions created by agricultural wage work contribute to the production of vicious cycles of food insecurity that are especially critical for poorer and food-deficit households and those where women are the main earners, due to their higher workloads.

The findings presented in this paper are context-specific. However, they provide useful insights for the study of the gendered determinants of food security that can be applied in different settings. This analysis casts a different light on the relation between women and food security, relative to that shed by the instrumentalist literature. On the one hand, it shows how women are a differentiated group embedded in a broader socio-economic context, and, on the other, how food insecurity is produced by different forms of deprivation interacting over time. Lack of decent employment and infrastructure make people income and time poor, and unable to meet their food needs. Food vulnerability is shaped by gender, age, and class in Cabo Delgado, and women carry out paid and unpaid work in this socio-economic setting. Food security analyses need to integrate perspectives on how social relations and inequality produce and shape food insecurity over time.

Despite the novel use of concepts and methods, limitations persist. The analysis of production of food insecurity over time is constrained by reliance on data collected within one year, which does not allow for a longer-term perspective on food security. Mixed-method longitudinal 
studies are needed to better capture the gendered dynamics of food insecurity. In addition, methodological reflections on how to mix methods effectively to conduct gender analyses of food security are necessary to strengthen the integration of qualitative and quantitative methods in this area of study.

\footnotetext{
${ }^{\mathrm{i}}$ Instrumental approaches to gender equality hinge on two corollary arguments. First, gender equality is seen as conducive to poverty reduction, a proposition that emerges from literature studying the relationship between gender equality and economic development (Duflo 2012). Second, gender equality is seen as contributing to wellbeing promotion, which emerges from studies highlighting the importance of women (mothers) in domains such as child nutrition, health and education (Smith et al. 2003). This study scrutinizes the latter, with a specific focus on food and nutrition outcomes.

ii The studies reviewed in this section are of two types. One group is that of early studies that are widely cited in subsequent literature. The other is composed of a selection of the most recent literature on the topic, especially that focusing on countries and regions in sub-Saharan Africa. Key academic journals in development studies, economics and nutrition were searched as well as relevant grey literature.

iii Women's status is assessed by two indexes: women's relative decision-making power and societal gender equality. The first is calculated on the basis of four household-level dimensions of gender (in)equality: whether a woman works for cash or not (operationalised as a dummy variable), women's age at first marriage, percent difference in the woman's and her partner's age and difference in the woman's and her partner's year of education. The second is based on three societal-level dimensions: difference in wasting between boys and girls under 5 years old, difference in vaccination score between boys and girls under 5 years old and difference in years of education of adult women and men.

iv See for example the Guardian on the debt crisis in Mozambique, on 27 ${ }^{\text {th }}$ October 2016 https://www.theguardian.com/global-development/2016/oct/27/mozambique-debt-crisis-first-sign-globalfinancial-shockwave

${ }^{v}$ When updated and comprehensive lists of households are not available, research practice suggests that a random point is chosen to then select households along a direction from the starting point (Bennett et al. 1991). Given the structure of the villages where the survey was conducted - all divided in similarly-sized sub-units - a variation of the conventional method was used and households were randomly selected in equal numbers from each sub-unit of a village or neighbourhood. Thus 40 households were selected in each district, using a stratified random sample. ${ }^{v i}$ Cash-earning women are those who engaged with paid work and/or cash-earning activities in the year before the interview.

vii This interpretation is also supported by the evidence on gendered cash allowances, which, as discussed in section 4.1, suggests that men's incomes are those that households tend to rely on to meet their basic needs.

viii Wealth was measured by an asset index. Women were asked questions about possession of specific assets in their household, such as TV, fridge, framed bed, and about housing conditions. The asset index was constructed
} 
using principal component analysis, following Filmer and Pritchett (2001), Wall and Johnston (2008) and Abreu (2012). The first quartile is the poorest and the fourth the wealthiest.

${ }^{\text {ix }}$ It would be interesting to assess whether household composition shapes food security independently of household wealth. However, it is slippery to test this association as family members who can take up household and care work may not live in the same household, which was commonly observed in the qualitative phases of research. The definition of the household used in this study captures the members normally living in the same house.

${ }^{\mathrm{x}}$ Qualitative interviews revealed that households often use revenue from off-farm activities to hire agricultural labour and increase production to, in turn, boost earnings from commercialisation of agricultural produce.

xi This observation is in line with data collected by SETSAN (Technical Secretariat for Food and Nutrition Security) in 2009 that show that 70 per cent of the respondents said that lack of human labour was the main reason for not cultivating land in the province of Cabo Delgado (WFP 2010).

xii O'Laughlin (2013) uses this terminology - 'social costs of production' - to refer to the externalisation of the costs of production that capitalist production imposes onto governments, civil society, markets and households. In this context, I use it to indicate that many of the social costs of production are borne by households.

xiii Reliance on non-commodified production, recourse to casual wage labour, spatial and social dualism in the provisioning of health care and racialised understanding of the causes of disease are the four tendencies that O'Laughlin (2013) identifies as lying at the basis of reproduction of health inequality in southern Africa today. Due to the purposes of the discussion and relevance in the context of Cabo Delgado, I have focused on two of these tendencies.

\section{References}

Abreu, A. J. G. (2012) 'Migration and Development in Contemporary Guinea-Buissau: A Political Economy Approach’, PhD thesis in Economics, SOAS University of London.

Ballard, T., Coates, J., Swindale, A. and Deitchler, M. (2011) 'Household Hunger Scale: Indicator Definition and Measurement Guide’, Washington DC: Food And Nutrition Technical Assistance Project (FANTA).

Bardasi, E., and Wodon, Q. (2006). Poverty reduction from full employment: A time use approach., in Blackden, C. M. and Q. Wodon (eds.) (2006) Gender, Time Use and Poverty in Sub-Saharan Africa, Washington DC: The World Bank.

Bennett, S., Woods, T., Liyanage, W. M., and Smith, D. L. (1991) 'A simplified general method for cluster-sample surveys of health in developing countries', World Health Stat Q, 44(3): 98-106.

Blackden, C. M. and Q. Wodon (eds.) (2006) Gender, Time Use and Poverty in Sub-Saharan Africa, Washington DC: The World Bank.

Bryceson, D. F. (2006) 'Ganyu Casual Labour, Famine and HIV/AIDS in Rural Malawi: Causality and Casualty’, The Journal of Modern African Studies, 44(2): 173-202.Clark, G. (1994) Onions are my husband! Survival and Accumulation by West African Market Women, London: The University of Chicago Press.

Cunguara, B., \& Hanlon, J. (2012). Whose wealth is it anyway? Mozambique's outstanding economic growth with worsening rural poverty. Development and change, 43(3), 623647. 
Datar, A., Nicosia, N., \& Shier, V. (2014). Maternal work and children's diet, activity, and obesity. Social Science \& Medicine, 107, 196-204.

Deitchler, M., Ballard, T., Swindale, A. and Coates, J. (2010) 'Validation of a measure of household hunger for cross-cultural use', Washington DC: Food and Nurtrition Technical Assistance II Project (FANTA).

Deitchler, M., Ballard, T., Swindale, A. and Coates, J. (2011) 'Introducing a simple measure of household hunger for cross-cultural use', Technical Note 12, Washington DC: Food And Nutrition Technical Assistance Project (FANTA).

Devereux, S., (2009) Seasonality and Social Protection in Africa, Working Paper 11 (Jan 2009), Future Agricultures.

Demographic Health Survey (DHS) (2011). Ministerio da Saude (MISAU), Instituto Nacional de Estatística (INE) e ICF International (ICFI). Moçambique Inquérito Demográfico e de Saúde 2011. Calverton, Maryland, USA: MISAU, INE e ICFI.

Doss, C. (2005) 'The Effects of Intrahousehold Property Ownership on Expenditure Patterns in Ghana', Journal of African Economies, 15(1): 149-180.

Duflo, E. (2003) 'Grandmothers and Granddaughters: Old-Age Pensions and Intrahousehold Allocation in South Africa’, The World Bank Economic Review,17(1): 1-25.

Duflo, E. (2012). Women empowerment and economic development. Journal of Economic Literature, 50(4), 1051-1079.

Duvendack, M., \& Palmer-Jones, R. (2016). Micro-Finance, women's empowerment and fertility decline bangladesh: How important was women's agency? The Journal of Development Studies. doi:10.1080/00220388.2016.1205731

Fejerskov, A. M. (2016). The Influence of Established Ideas in Emerging Development Organisations: Gender Equality and the Bill and Melinda Gates Foundation. The Journal of Development Studies, 1-16. DOI: 10.1080/00220388.2016.1199859

Filmer, D. \& Pritchett, L. (2001). Estimating Wealth Effects Without Expenditure Data - Or Tears: An Application to Educational Enrolments in States of India', Demography, 38(1), 115-132.

Garikipati, S., Johnson, S., Guérin, I., \& Szafarz, A. (2016). Microfinance and gender: issues, challenges and the road ahead. The Journal of Development Studies, 1-8. DOI: 10.1080/00220388.2016.1205736

Gideon, J., and Porter, F. (2015). Unpacking 'women’s health'in the context of PPPs: A return to instrumentalism in development policy and practice?. Global Social Policy, 16(1), 68-85.

Jackson, C. and Palmer-Jones, R. (1998) 'Work intensity, gender and well-being', UNRISD Discussion Paper no. 96. Geneva: UN Research Institute for Social Development.

Johnston, D.; Stevano, S.; Malapit, H. J.; Hull, E.; Kadiyala, S. (2015) Agriculture, gendered time use, and nutritional outcomes: A systematic review. IFPRI Discussion Paper 1456. Washington, D.C.: International Food Policy Research Institute (IFPRI). 
Jones, A. D., Agudo, Y. C., Galway, L., Bentley, J., \& Pinstrup-Andersen, P. (2012). Heavy agricultural workloads and low crop diversity are strong barriers to improving child feeding practices in the Bolivian Andes. Social Science \& Medicine, 75(9), 1673-1684.

Kadiyala, S., Harris, J., Headey, D., Yosef, S. and Gillespie, S. (2014) 'Agriculture and Nutrition in India: Mapping Evidence to Pathways', Annals of the New York Academy of Sciences 1331:43-56.

Lépine, A. and Strobl, E. (2013) 'The effect of women's bargaining power on child nutrition in rural Senegal', World Development, 45: 17-30.

Malapit, H. J. L., Kadiyala, S., Quisumbing, A. R., Cunningham, K., \& Tyagi, P. (2015). Women's empowerment mitigates the negative effects of low production diversity on maternal and child nutrition in Nepal. The Journal of Development Studies, 51(8), 1097-1123.

Martin, M. A., \& Lippert, A. M. (2012). Feeding her children, but risking her health: The intersection of gender, household food insecurity and obesity. Social science \& medicine, 74(11), 1754-1764.

MPD/DNEAP (2010) 'Poverty and Well-being in Mozambique: The Third National Assessment (2008-9)’. Maputo: Ministry of Planning and Development.

Meagher, K. (1995) 'Crisis, Informalization and the Urban Informal Sector in Sub-Saharan Africa’ Development and Change, 26(2): 259-284.

Meagher, K. (2010) 'The empowerment trap: gender, poverty and the informal economy in sub-Saharan Africa', in: Chant, Sylvia, (ed.) The International Handbook of Gender and Poverty: Concepts, Research, Policy, Edward Elgar Publishing, Gloucestershire, UK.

Meagher, K. (2016) The Scramble for Africans: Demography, Globalisation and Africa's Informal Labour Markets, The Journal of Development Studies, 52:4, 483-497.

MICS (2008) Multiple Indicator Cluster Survey (MICS) 2008, Maputo, Mozambique: Instituto Nacional de Estatistica: Maputo, Mozambique.

Moore, H. L. and Vaughan, M. (1994) Cutting down trees: gender, nutrition, and agricultural change in the Northern Province of Zambia, 1890-1990, Portsmouth, NH: Heinemann.

O'Laughlin, B. (1998). Missing men? The debate over rural poverty and women households in Southern Africa. The Journal of Peasant Studies, 25(2), 1-48.

O’Laughlin, B. (2007) 'A Bigger Piece of a Very Small Pie: Intrahousehold Resource Allocation and Poverty Reduction in Africa'. Development and Change, 38(1): 21-44.

O'Laughlin, B. (2013) 'Land, Labour and the Production of Affliction in Rural Southern Africa', Journal of Agrarian Change, 13(1): 175-196.

Pontara, N. (2001) 'Gender and Poverty in Mozambique: A Review of Empirical Literature', background paper, Study on the Feminisation of Poverty in Mozambique, ILO and UNDP. 
Quisumbing, A., Brown, L. R., Feldstein, H. S., Haddad, L., \& Peña, C. (1995) Women: The key to food security, 431-440, Washington DC: International Food Policy Research Institute (IFPRI).

Quisumbing, A. R. and Maluccio, J. A. (2000) 'Intrahousehold Allocation and Gender Relations: New Empirical Evidence from Four Developing Countries’, FCND Working Paper 84, IFPRI, Washington D.C.

Quisumbing, A. R. and Meinzen-Dick, R. S. (2001) Empowering women to achieve food security, (No. 6), Washington DC: International Food Policy Research Institute (IFPRI).

Ricci, J. A., Jerome, N. W., Sirageldin, I., Aly, H., Moussa, W., Galal, O., \& Kirksey, A. 1996. "The Significance of Children's Age in Estimating the Effect of Maternal Time Use on Children's Well-being.” Social Science and Medicine 42 (5): 651-659.

Ruel, M. T. (2002) 'Is dietary diversity an indicator of food security or dietary quality? A review of measurement issues and research needs', FCND Discussion Paper 140, Washington DC: International Food Policy Research Institute (IFPRI).

Ruel, M. T., Alderman, H., \& Maternal and Child Nutrition Study Group. (2013). Nutritionsensitive interventions and programmes: how can they help to accelerate progress in improving maternal and child nutrition?. The Lancet, 382(9891), 536-551.

Sen, A. (1981) Poverty and Famines: An Essay on Entitlement and Deprivation, Oxford: Clarendon Press.

Smith, L., Alderman, H. and Aduayom, D. (2006) Food Insecurity in Sub-Saharan Africa: New Estimates From Household Expenditure Surveys, Research report number 146, Washington DC: International Food Policy Research Institute (IFPRI).

Smith, L. C., Ramakrishnan, U., Ndiaye, A., Haddad, L., and Martorell, R. (2003) 'The importance of women's status for child nutrition in developing countries’, Vol. 131. International Food Policy Research Institute.

Stevano, S. (2013) 'Mulheres no Processamento da Castanha de Caju: Reflexões sobre as Sociedades Agrárias, Trabalho e Género ne Província de Cabo Delgado’, in Desafios para Moçambique 2013, Maputo: IESE.

Stevano, S., Johnston, D., Kadiyala, S., Malapit, H. and Hull, E. (forthcoming) 'Time use in agriculture nutrition research: Conceptualisation, operationalisation and interpretation', manuscript submitted for publication

Thomas, D. (1990) ‘Intra-household resource allocation: An inferential approach’ The Journal of Human Resources, 25 (4): 635-664.

Thomas, D. (1997) 'Incomes, Expenditures and Health Outcomes: Evidence on Intrahousehold Resource Allocation', in Haddad, L., Hoddinott, J. and Alderman, H. (1997) 'Intrahousehold Resource Allocation in Developing Countries, Models, Methods and Policy’, IFPRI, The John Hopkins University Press, Baltimore and London.

van den Bold, M., Quisumbing, A. R. and Gillespie, S. (2013) 'Women’s Empowerment and Nutrition: An Evidence Review’, IFPRI Discussion paper 01294, Washington D.C.: International Food Policy and Research Institute (IFPRI). 
van den Bold, M., Dillon, A., Olney, D., Ouedraogo, M., Pedehombga, A., \& Quisumbing, A. (2015). Can integrated agriculture-nutrition programmes change gender norms on land and asset ownership? Evidence from Burkina Faso. The Journal of Development Studies, 51(9), 1155-1174.

Wall, M., \& Johnston, D. (2008). Counting Heads or Counting Televisions: Can Asset-based Measures of Welfare Assist Policy-makers in Russia?. Journal of Human Development, 9(1), 131-147.

Wilson, K. (2015). Towards a Radical Re-appropriation: Gender, Development and Neoliberal Feminism. Development and Change, 46(4), 803-832.

World Food Programme (2010) Comprehensive Food Security and Vulnerability Analysis, Republic of Mozambique, Maputo: The World Food Programme (WFP).

Whitehead, A. (2009) 'The gendered impacts of liberalisation policies on African agricultural economies and rural livelihoods' in Razavi, S. (Ed.). (2010). The Gendered Impacts of Liberalization: Towards" Embedded Liberalism"?. Routledge New York: United Nations Research Institute for Social Development (UNRISD).

Ziol-Guest, K. M., Dunifon, R. E., \& Kalil, A. (2013). Parental employment and children's body weight: mothers, others, and mechanisms. Social Science \& Medicine, 95, 52-59. 